\title{
Generation of a transient non-culturable state in Pseudomonas putida during detoxification of $\boldsymbol{N}$-ethylmaleimide
}

\author{
Sabine Tötemeyer, ${ }^{1}$ Keith Barrett-Bee ${ }^{2}$ and lan R. Booth ${ }^{1}$ \\ Author for correspondence: Ian R. Booth. Tel: +44 1224 273152. Fax: +44 1224273144. \\ e-mail: gen118@abdn.ac.uk
}

1 Department of Molecular \& Cell Biology, University of Aberdeen, Marischal College, Aberdeen AB9 1AS, UK

2 Zeneca Pharmaceuticals, Mereside, Alderley Park, Macclesfield SK10 4TG, UK

\begin{abstract}
The response of Pseudomonas putida to the electrophile $\boldsymbol{N}$-ethylmaleimide (NEM) has been investigated. Treatment with low levels of NEM (20-30 $\mu \mathrm{M})$ led to transient growth inhibition followed by recovery of normal growth. Stationary phase cells acquired resistance to NEM; one component of this tolerance was a more rapid metabolism of NEM. In exponential phase cells, the period of growth inhibition was associated with detoxification of NEM. Detoxification was biphasic and cells lost the ability to form colonies on minimal agar plates during the first phase of detoxification. Full viability was retained on MacConkey agar. Peptones are the active components in MacConkey medium. Addition of peptones to minimal agar restored colonyforming ability, but each peptone source had a different efficiency. These data suggest that a deficiency in the ability to assimilate nitrogen is a consequence of NEM treatment.
\end{abstract}

Keywords: Pseudomonas putida, N-ethylmaleimide, glutathione, detoxification, stationary phase

\section{INTRODUCTION}

In a wide range of bacteria, the detoxification of electrophiles such as methylglyoxal, $N$-ethylmaleimide (NEM) and chlorodinitrobenzene proceeds through the formation of a glutathione adduct (Cooper, 1984; Murata et al., 1989; Mannervik \& Danielson, 1988; Summer \& Goggelmann, 1980). A further step in protection against electrophiles is the activation of the potassium efflux systems $\mathrm{KefB}$ and $\mathrm{KefC}$ and a resulting acidification of the cytoplasm (Ferguson et al., 1995). The potassium efflux systems $\mathrm{KefB}$ and $\mathrm{KefC}$ are inhibited by glutathione and activated by glutathione adducts (Meury \& Kepes, 1982; Bakker et al., 1987; Elmore et al., 1990; Ferguson et al., 1993). KefC activity is widespread in Gram-negative bacteria (Douglas et al., 1991), which suggests its importance in cell physiology, and the role of $\mathrm{KefC}$ in survival of Escherichia coli during detoxification of environmental electrophiles has been demonstrated (Ferguson et al., 1993; Y. Nikolaev and others, unpublished).

The pseudomonads have a marked capacity for the metabolism of toxic compounds, some of which are electrophiles. Pseudomonads are found in the root

Abbreviation: NEM, $\mathrm{N}$-ethylmaleimide. rhizosphere and have recently been implicated in the detoxification of the electrophile alachlor (Zablotowicz et al., 1995). Many bacteria commonly associated with the root rhizosphere, including Pseudomonas putida and Pseudomonas fluorescens, possess glutathione $S$-transferase activity capable of conjugating alachlor to glutathione. In addition, both $P$. putida and $P$. fuorescens metabolize the glutathione conjugate after its excretion into the periplasm, where it is a substrate for $\gamma$-glutamyltransferase (Zablotowicz et al., 1995). Eventually the conjugate is broken down to release the glutamate and glycine moieties, leaving the cysteine-alachlor conjugate to accumulate in the medium. P. putida has also been reported to have very high levels of glyoxalase I, which breaks down the hemithioacetal formed between the natural electrophile methylglyoxal and glutathione (Rhee et al., 1987). This detoxification process takes place in the cytoplasm. These detoxification systems may be complemented by glutathione-adduct-gated potassium efflux systems (Douglas et al., 1991), which play a major role in protecting E. coli cells against the toxic effects of methylglyoxal and NEM (Ferguson et al., 1993, 1995; G. P. Ferguson and others, unpublished).

In the light of the above, we were interested in investigating the response of $P$. putida to NEM as a model synthetic electrophile. The data presented here show that 
cells recover rapidly from exposure to low concentrations of NEM and that they are able to detoxify this electrophile. During the detoxification process, cells undergo a transient loss of ability to form colonies on minimal agar plates, but not on MacConkey agar. The active component of the MacConkey medium is the peptone, which when added to minimal agar restores colony-forming ability. Stationary phase cells do not show the transient loss of colony-forming capacity and show accelerated detoxification of NEM. Stationary phase cells are also more resistant to higher concentrations of NEM.

\section{METHODS}

Bacterial strains and culture conditions. Pseudomonas putida (NCIMB 9494) was obtained from the NCIMB, University of Aberdeen, UK. Medium $\mathrm{K}_{x}$ (Epstein \& Kim, 1971), where $x$ is the concentration of potassium $\left(\mathrm{mmol}^{-1}\right)$, was used for growth and transport experiments as indicated. The carbon source was citrate $(0 \cdot 2 \%, \mathrm{w} / \mathrm{v})$ and all experiments were carried out at $30^{\circ} \mathrm{C}$. Cultures were grown overnight in a shaking incubator and then diluted into fresh growth medium, grown into midexponential phase $\left(\mathrm{OD}_{650}=0.5\right.$; measured using a PharmaciaLKB Novospec II spectrophotometer) and diluted to an $\mathrm{OD}_{650}$ of 0.1 with fresh pre-warmed growth medium. Additions of electrophiles were made from fresh solutions as described in the text and in legends to figures. NEM was dissolved in $50 \%(\mathrm{v} / \mathrm{v})$ ethanol. Measurements of growth were made by monitoring the $\mathrm{OD}_{650}$ of the cell suspension. Cell size and morphology were observed and analysed by light microscopy using an Olympus $\mathrm{BH}-2$ microscope and a CCTV video analysis system linked to a BBC computer (Gray \& Morris, 1992).

For analysis of growth-phase-dependent gene expression, the above growth regime was modified. Cultures were grown overnight and then diluted into fresh growth medium and grown into mid-exponential phase $\left(\mathrm{OD}_{650}=0.5\right)$ to ensure the loss of proteins that had been expressed in response to entry into the stationary phase. The cultures were then diluted to an $\mathrm{OD}_{650}$ of $0 \cdot 1$ with fresh pre-warmed growth medium and the growth was monitored. At intervals, aliquots were taken, diluted to an $\mathrm{OD}_{650}$ of $0 \cdot 1$ and incubated with $20 \mu \mathrm{M}$ NEM. Replicate samples were taken for serial dilutions to assess cell viability.

Viable counts and recovery media. Cell viability was determined by making serial dilutions into $K_{10}$ medium lacking citrate and spotting $5 \mu \mathrm{l}$ aliquots (in triplicate) onto $\mathrm{K}_{10}$ plates followed by incubation for $24 \mathrm{~h}$ at $30^{\circ} \mathrm{C}$. The mean and standard deviation of the number of viable colonies $\mathrm{ml}^{-1}$ is plotted on all figures. The limit of detection of this technique is 200 viable cells $\mathrm{ml}^{-1}$. All experiments were replicated several times, but each figure represents a typical experiment. Recovery media were different for some experiments (as indicated in the text and legends): LK medium was as described by Rowland $e t$ al. (1984); MacConkey broth was made up following the manufacturer's instructions; additions of peptone, bile salts, $\mathrm{NaCl}$, neutral red and crystal violet to $\mathrm{K}_{10}$ medium were at the concentrations found in MacConkey medium.

Uptake of $\left[{ }^{14} \mathrm{C}\right] \mathrm{NEM}$. Cultures in mid-exponential phase were diluted into fresh pre-warmed medium to a final $\mathrm{OD}_{650}$ of $0 \cdot 1$ and $\left[2-{ }^{14} \mathrm{C}\right] \mathrm{NEM}$ was added to a final concentration of $25 \mu \mathrm{M}$. Samples $(500 \mu \mathrm{l})$ were taken at intervals, filtered rapidly (cellulose nitrate; $0.45 \mu \mathrm{m}$ ) and washed with two $3 \mathrm{ml}$ aliquots of pre-warmed $K_{10}$ growth medium. The filters were then dried and transferred to scintillation vials with $3 \mathrm{ml}$ scintillant (Ultima Gold, Packard) and the radioactivity was determined on a Packard 300C liquid scintillation counter.
Materials. $\left[2,3-{ }^{14} \mathrm{C}\right] \mathrm{NEM}$ was obtained from Amersham and NEN; MacConkey agar, Bactopeptone and proteose peptone were obtained from Difco; bile salts no. 3 were from Oxoid; peptone no. I and IV, neutral red and crystal violet were from Sigma. Components of defined media were from BDH.

\section{RESULTS}

\section{A transient non-culturable state after treatment with NEM}

$P$. putida was tested for its ability to recover from exposure to $20-100 \mu \mathrm{M}$ NEM. After growth to mid-exponential phase in $\mathrm{K}_{\mathbf{1 0}}$ medium plus citrate, the cultures were diluted into fresh pre-warmed medium containing 20 $100 \mu \mathrm{M}$ NEM and the growth rate and cell viability were determined. The addition of the toxic electrophile resulted in growth inhibition (Fig. 1a). After a lag phase of $250 \pm 70 \mathrm{~min}$ and $410 \pm 60 \mathrm{~min}$ in the presence of 20 and $30 \mu \mathrm{M}$ NEM, respectively, exponential growth at a rate close to, but slower than, that of untreated cultures (specific growth rates were $0 \cdot 89 \pm 0.03 \mathrm{~h}^{-1}, 0 \cdot 71 \pm 0 \cdot 01 \mathrm{~h}^{-1}$ and $0.62 \pm 0.07 \mathrm{~h}^{-1}$, for control, $20 \mu \mathrm{M}$ incubation and $30 \mu \mathrm{M}$ incubation, respectively) was observed. Addition of $100 \mu \mathrm{M}$ NEM prevented growth over a period of $36 \mathrm{~h}$. These data show that $P$. putida is able to recover from exposure to low concentrations of the toxic electrophile, but is very sensitive to higher concentrations.

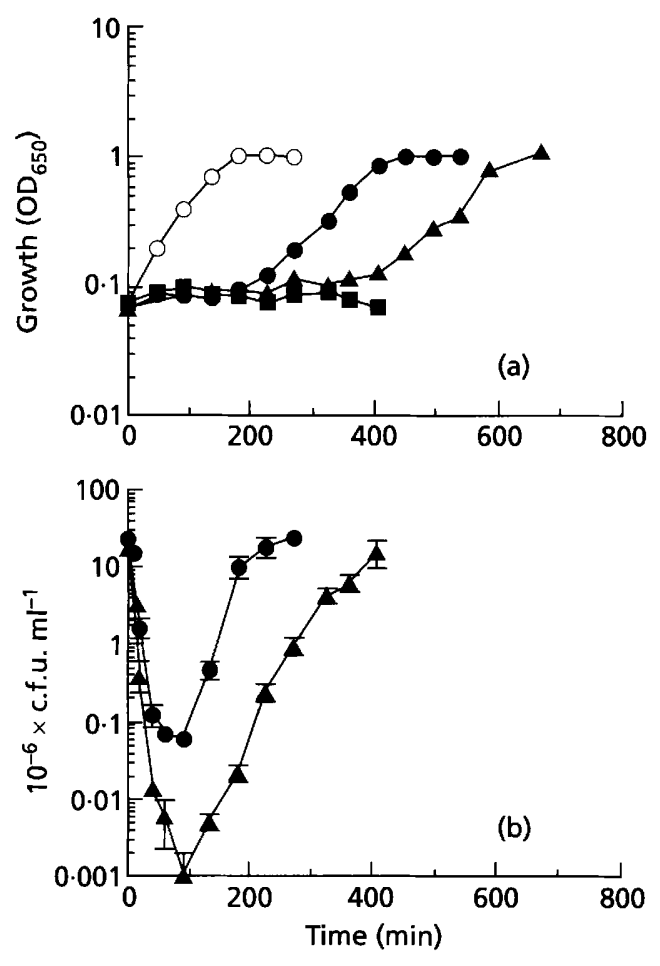

Fig. 1. Response of growth and apparent viability of $P$. putida to exposure to NEM in the exponential growth phase. Cultures were prepared and growth was analysed as described in Methods. (a) Cell growth. $O$, Control culture, no NEM; $\bullet$, $20 \mu \mathrm{M}$ NEM; $\boldsymbol{\Delta}, 30 \mu \mathrm{M}$ NEM;, $100 \mu \mathrm{M}$ NEM. (b) Apparent viability. The number of cells capable of forming colonies was determined as described above; symbols are as in (a). 

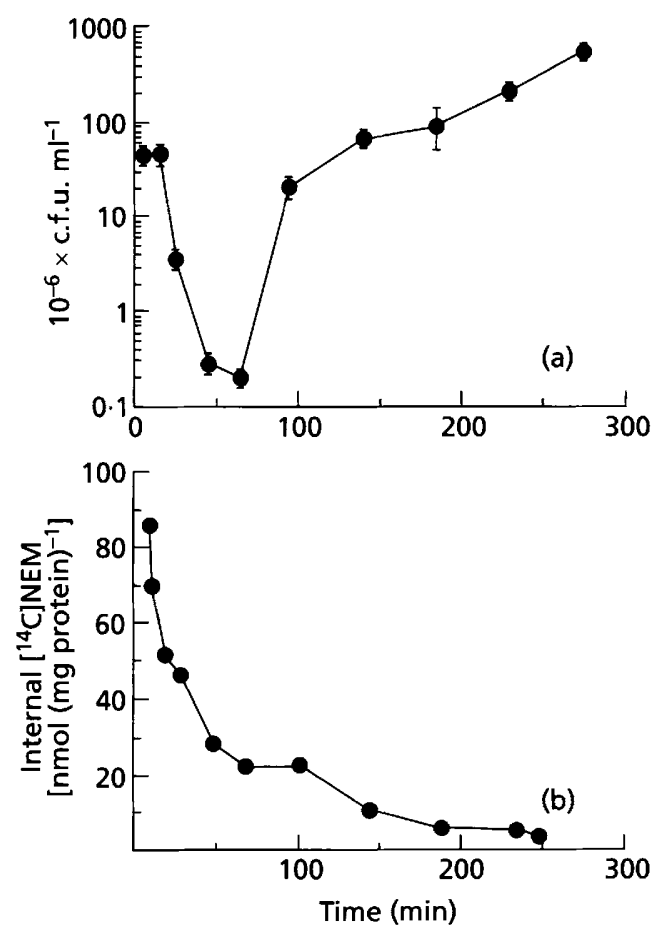

Fig. 2. Rapid NEM breakdown in exponentially growing $P$. putida cells during the time period of rapid apparent loss of viability. Cultures were prepared as described in Methods. (a) Apparent viability in the presence of $20 \mu \mathrm{M}$ NEM and (b) [2,3$\left.{ }^{14} \mathrm{C}\right] \mathrm{NEM}$ associated with cells were measured as described in Methods.

Cell viability was measured to determine whether there was any killing during the lag phase. Cultures of $P$. putida appeared to lose viability rapidly in the presence of NEM (Fig. 1b), but they subsequently recovered. The apparent decrease in the plate counts was greater for $30 \mu \mathrm{M}$ NEM than for $20 \mu \mathrm{M}$ (Fig. 1b). An increase in c.f.u was observed 90 min after adding $20 \mu \mathrm{M}$ NEM and 150 min after adding $30 \mu \mathrm{M}$ NEM. The culture recovered to give the viable plate count observed prior to addition of NEM. In the presence of $100 \mu \mathrm{M}$ NEM, a rapid decrease in cell viability occurred and no recovery was observed (data not shown). These data fit with the failure of the $\mathrm{OD}_{650}$ of the treated culture to increase over a $36 \mathrm{~h}$ period (Fig. 1a).

The observed increase in colony counts in cultures treated with low concentrations of NEM was not due to growth since the rate of recovery was clearly higher than the growth rate during exponential growth. The specific growth rates required to explain the recovery if occurring by growth of residual surviving cells were $3.54 \pm 0 \cdot 17 \mathrm{~h}^{-1}$ and $1.87 \pm 0.47 \mathrm{~h}^{-1}$, respectively, for 20 and $30 \mu \mathrm{M}$ NEM. These rates are far higher than the exponential growth rate observed in growing untreated cultures of $P$. putida. Total protein concentration did not change during the recovery period; the protein content of the culture remained constant at $29 \mu \mathrm{g} \mathrm{ml}^{-1}$. During the recovery phase, no change in cell morphology was observed (data not shown). These data suggest that no growth is occurring during the period of non-culturability and that

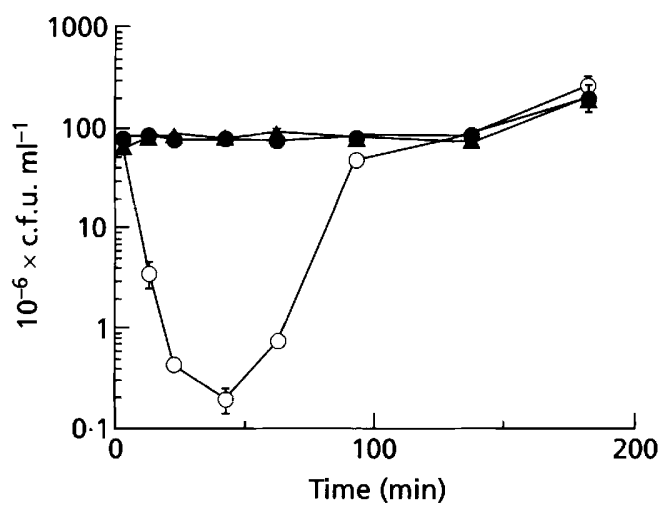

Fig. 3. Prevention of the transient loss of colony-forming ability of exponentially growing $P$. putida. The apparent cell viability on $\mathrm{K}_{10}(\mathrm{O})$, peptones $\left(17 \mathrm{~g}\right.$ Bacto peptone $\mathrm{I}^{-1} ; 3 \mathrm{~g}$ proteose peptone $\left.\mathrm{I}^{-1} ; \boldsymbol{\theta}\right)$ and MacConkey $(\boldsymbol{\Delta})$ solid medium is shown.

the change in viable counts was not due to transient suppression of cell division followed by fragmentation to cause a large increase in c.f.u. The transient loss of culturability occurred despite the removal of the NEM during serial dilution for plating. Thus, it represents damage inflicted by the electrophile during the incubation.

\section{Breakdown of NEM}

The recovery of the cells, and the concentration dependence of the lag prior to recovery, implied that the NEM was detoxified by the cells. The breakdown of NEM was investigated by monitoring the internal concentration of radiolabelled NEM. Optical density and cell viability measurements were performed on a parallel culture incubated under the same conditions with unlabelled NEM. The NEM was taken up into the cells very rapidly, reached a peak and then declined. The decrease in radiolabel was biphasic (Fig. 2): an initial rapid release followed by a phase of slower decrease. The rapid phase of NEM detoxification corresponds with the period of growth inhibition and with the rapid decline in culturability of the cells. The increase in colony counts was coincident with the onset of the second phase of detoxification. These data show that the cells are metabolizing NEM even though they are in a non-culturable state.

\section{Suppression of the non-culturable state}

The loss of the culturable state was observed on citratebased minimal media, identical to the incubation media. The effects of different supplements and alternative media were investigated to determine whether the non-culturable state had a simple metabolic basis. Non-culturable cells were observed at both high and low potassium concentrations in the recovery plates and when LK broth was substituted for the minimal medium. However, viability did not decline if recovery was made on MacConkey agar base or on a mixture of Bacto peptone/ proteose peptone, the peptone constituents of MacConkey 

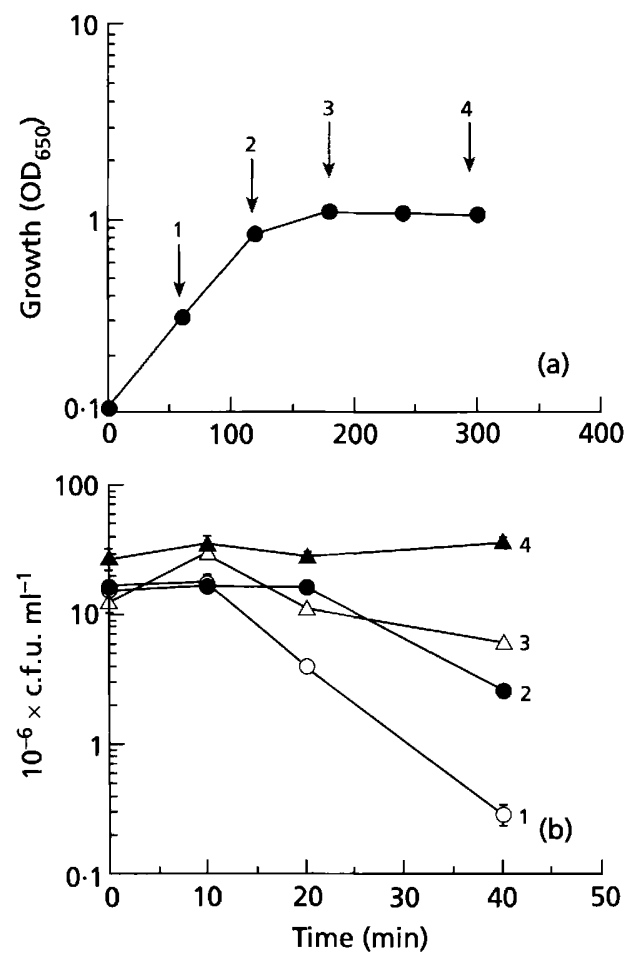

Fig. 4. Consequences of exposure to NEM are growth-phase dependent. Cultures were prepared as described in Methods with specific precautions to allow the accumulated stationary phase proteins to be diluted out by growth into exponential phase prior to inoculation of the flasks for the experiment. (a) Growth was monitored by measuring optical density. (b) At intervals (indicated by arrows), an aliquot of culture was taken diluted into fresh pre-warmed growth medium containing $20 \mu \mathrm{M}$ NEM, and the capacity of the cells to form colonies on $\mathrm{K}_{10}$ plates with citrate as sole carbon source was determined. 1, Mid-exponential phase; 2, late-exponential phase; 3, earlystationary phase; 4, stationary phase.

agar (Fig. 3). Not all peptone media had this effect since meat peptone and soya bean peptone were only partially effective. Addition of soya bean peptone to plates delayed the onset of the decline in plate counts and the lowest viable count observed did not reach values as low as those seen on citrate minimal medium. Other constituents of MacConkey base (bile salts, $\mathrm{NaCl}$, neutral red and crystal violet) were without effect on viability. That bile salts were without effect suggests that the basis of the lack of culturability is not simply damage to membranes leading to enhanced susceptibility to media components. These results demonstrate that specific components of the peptones of MacConkey agar base were required to maintain constant cell viability.

\section{Cultures of $\boldsymbol{P}$. putida are more resistant to NEM in stationary phase}

In general, cells in stationary phase are more resistant to various stresses, due to induction of gene products that confer protection (Matin, 1992). To determine if the response of $P$. putida to NEM is growth-phase dependent, growth and viability experiments with cultures in station-
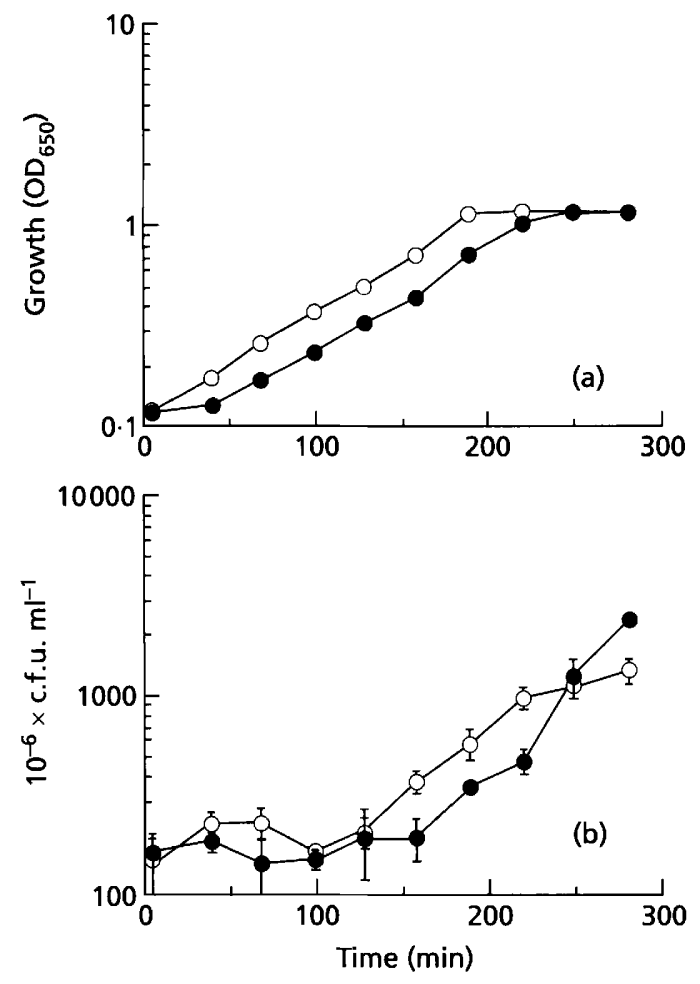

Fig. 5. Apparent growth of $P$. putida after transfer to fresh growth medium. Cells from a $16 \mathrm{~h}$ stationary phase culture were transferred to fresh pre-warmed growth medium in the presence (filled symbols) and absence (open symbols) of $20 \mu \mathrm{M}$ NEM. Samples were taken at intervals for (a) $O D_{650}$ and (b) viable count measurements as described in Methods.

ary phase were performed. Cells of $P$. putida entering the stationary phase of growth acquired resistance to NEM. Thus, the decline in apparent viability was not evident in cells that had entered the stationary phase (Fig. 4). The basis of the tolerance of NEM by stationary phase cultures was investigated.

Stationary phase cells (taken $16 \mathrm{~h}$ after inoculation) were smaller than exponential phase cells in accordance with previous studies (Givskov et al., 1994a). Viable counts for the same optical density were consistently two- to threefold greater than for exponential phase cultures. Furthermore, when cells were diluted into fresh growth medium there followed a steady increase in the $\mathrm{OD}_{650}$ that was not matched by increasing viable cell numbers (Fig. 5). The presence of NEM caused a short lag before the $\mathrm{OD}_{650}$ increased, but otherwise the pattern was similar to that observed with the untreated control. When the viability of such cells incubated with NEM was analysed, it was observed that viability was not affected by the presence of NEM, i.e. stationary phase cells did not show the transient decline in apparent viability observed with exponential phase cultures (Fig. 6). Parallel incubations with inocula from exponential phase cultures exhibited the same transient decline in viability reported above (Fig. 6). Incubation of stationary phase inocula with higher concentrations of NEM $(100 \mu \mathrm{M})$ resulted in a rapid loss of viability after $20 \mathrm{~min}$, indicating that there was a limit 

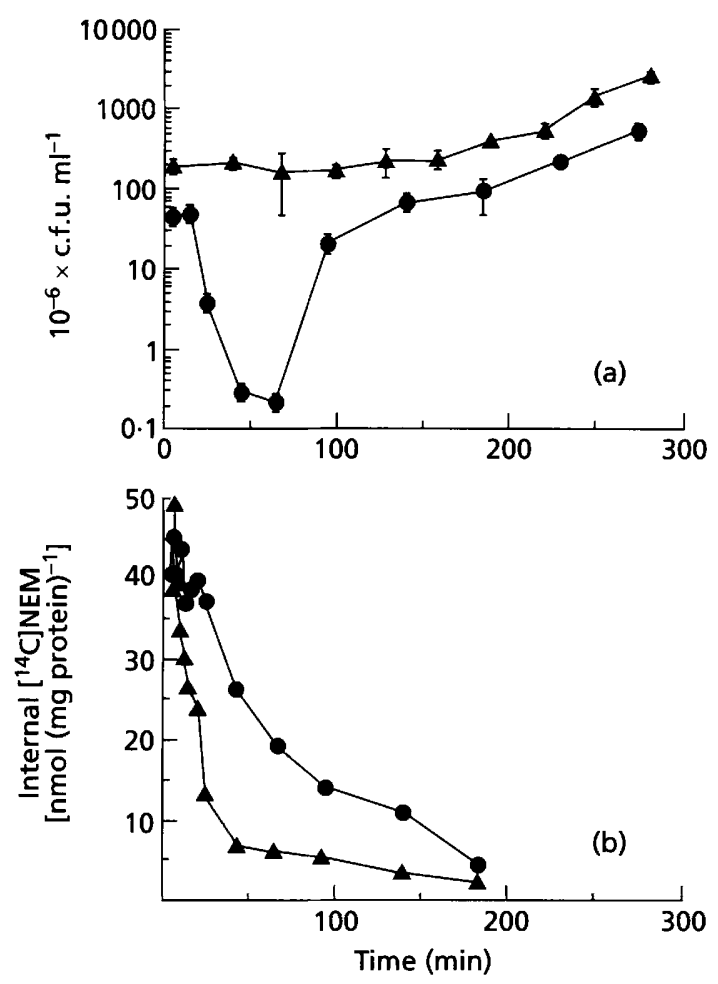

Fig. 6. Breakdown of intracellular NEM is more rapid in stationary phase than in exponential phase. Cultures in exponential $(\boldsymbol{O})$ and stationary $(\boldsymbol{\Delta})$ phase were prepared as described in Methods. The capacity to form colonies after exposure to $20 \mu \mathrm{M}$ NEM (a) and $\left[2,3-{ }^{14} \mathrm{C}\right] \mathrm{NEM}$ associated with cells (b) were measured as described in Methods.

to the acquired tolerance of the stationary phase cells (data not shown). Inhibitors of protein synthesis caused a rapid loss of viability in P. putida (see also Klotz \& Anderson, 1994) and thus the contribution of new protein synthesis to the acquisition of NEM tolerance could not be investigated. However, when cells were incubated with $\left[2,3-{ }^{14} \mathrm{C}\right] \mathrm{NEM}$, the stationary phase incubation exhibited a rapid phase of detoxification that was fivefold faster than that observed with exponential phase cultures (Fig. 6). Thus, part of the acquired tolerance of NEM in stationary phase cells could be explained by more rapid metabolism of NEM.

\section{DISCUSSION}

The data presented here show that $P$. putida will tolerate low concentrations of NEM through metabolic detoxification. The absence of glutathione-deficient mutants has prevented an in-depth analysis of the fate of NEM. However, the pattern of detoxification seen is similar to that observed in E. coli (D. McLaggan \& I. R. Booth, unpublished). In E. coli, the initial, rapid increase in cellassociated radioactivity is due to the formation of $N$ ethylsuccinimido-S-glutathione (ESG) in the cytoplasm; the rapid accumulation of counts derived from $\left[{ }^{14} \mathrm{C}\right] \mathrm{NEM}$ is dependent upon glutathione in the cytoplasm, and in the absence of this peptide the level of accumulation of radioactivity is much lower. The subsequent decline of counts is due to ESG breakdown with release of a nontoxic metabolite of NEM into the medium (D. McLaggan \& I. R. Booth, unpublished). This process can be accelerated by the addition of a reducing agent, dithiothreitol (Elmore et al., 1990). The third final phase represents the slow turnover of proteins labelled by NEM. The pattern of accumulation and release of radioactivity was similar in E. coli and $P$. putida, suggesting a similar general mechanism for the metabolism of NEM.

During the detoxification of NEM, we observed a transient loss of capacity to form colonies on agar plates. Peptide mixtures prevented the transient loss of culturability, suggesting either that specific peptides confer protection during the plating process or that NEM causes a specific impairment of nitrogen metabolism that is corrected by peptide feeding. That the latter is insufficient explanation for the data is suggested by the fact that different peptones, each of which is sufficient to support good growth, differ in their ability to prevent the loss of ability to form colonies on plates. The damage incurred by the cells does not appear to affect the membranes since the cells retain the ability to form colonies on MacConkey agar and on minimal medium containing bile salts. It may be that the glutathione pool of the cell is predominantly converted to ESG in NEM-treated $P$. putida and that this sensitizes cells to reactive oxygen intermediates that might otherwise be removed by reaction with glutathione. Peptone might then protect by cysteine-containing peptides absorbing reactive oxygen species.

It is well established that bacteria entering the stationary phase acquire resistance to a broad range of stressful conditions. In $E$. coli, the $\sigma^{38}$ protein plays a major role in controlling the expression of proteins that protect cells against stress (Hengge-Aronis, 1993), while less well characterized $P$. putida has been found to exhibit similar changes in behaviour to those observed in $E$. coli and to acquire stress tolerance after cultivation into the stationary phase (Givskov et al., 1994a). Several proteins are specifically induced upon entry into the stationary phase or during starvation for specific nutrients (Givskov et al., 1994b; Eberl et al., 1996). In P. putida, the stationaryphase-induced catalase is associated with increased tolerance of hydrogen peroxide (Klotz \& Anderson, 1994). Recently, a different sigma factor to that used in E. coli, $\sigma^{54}$, has been shown to be the regulator of at least one stationary-phase-associated gene (Kim et al., 1995). Thus, it was not surprising that $P$. putida acquired greater tolerance to NEM in stationary phase. A similar finding has been made for $E$. coli (Y. Nikolaev and others, unpublished) and the tolerance has been shown to be partly under the control of the $\sigma^{38}$ protein. It was, however, surprising to find that the stationary phase cells of $P$. putida metabolized NEM more rapidly (Fig. 6). This may explain the capacity of these cells to enlarge on suspension in pre-warmed growth medium, even in the presence of NEM.

In conclusion, we have shown that $P$. putida shows a marked capacity to detoxify NEM. Most surprising was 
the observation that the cells exhibited a transient loss of capacity to form colonies on solid agar, which could be prevented by specific peptone mixtures. Clearly the cells are sufficiently damaged so that they cannot form colonies, but as detoxification proceeds they recover sufficiently to grow from single cells into colonies.

\section{ACKNOWLEDGEMENTS}

$\mathrm{S}$. T. is a recipient of a BBSRC-CASE award with Zeneca Pharmaceuticals. The authors are grateful for the support provided by Debra McLaggan and Gail Ferguson in the completion of this work. The encouragement of other members of the laboratory and by the research group of Dr Nuala Booth is gratefully acknowledged.

\section{REFERENCES}

Bakker, E. P., Booth, I. R., Dinnbier, U., Epstein, W. \& Gajewska, A. (1987). Evidence for multiple $\mathrm{K}^{+}$-export systems in Eschericbia coli. J Bacteriol 169, 3743-3749.

Cooper, R. A. (1984). Metabolism of methylglyoxal in microorganisms. Annu Rev Microbiol 38, 49-68.

Douglas, R. M., Roberts, J. A., Munro, A. W., Ritchie, G. Y., Lamb, A. J. \& Booth, I. R. (1991). The distribution of homologues of the Escherichia coli $\mathrm{KefC} \mathrm{K}^{+}$-efflux system in other bacterial species. $J$ Gen Microbiol 137, 1999-2005.

Eberl, L., Givskov, M., Sternberg, C., Møller, S., Christiansen, G. \& Molin, S. (1996). Physiological responses of Pseudomonas putida KT2442 to phosphate starvation. Microbiology 142, 155-163.

Elmore, M. J., Lamb, A. J., Ritchie, G. Y., Douglas, R. M., Munro, A., Gajewska, A. \& Booth, I. R. (1990). Activation of potassium efflux from Eschericbia coli by glutathione metabolites. Mol Microbiol 4, 405-412.

Epstein, W. \& Kim, B. S. (1971). Potassium transport loci in Eschericbia coli K-12. J Bacteriol 108, 639-644.

Ferguson, G. P., Munro, A. W., Douglas, R. M., McLaggan, D. \& Booth, I. R. (1993). Activation of potassium channels during metabolite detoxification in Escherichia coli. Mol Microbiol 9, 1-7.

Ferguson, G. P., McLaggan, D. \& Booth, I. R. (1995). Potassium channel activation by glutathione-S-conjugates in Escherichia coli: protection against methylglyoxal is mediated by cytoplasmic acidification. Mol Microbiol 17, 1025-1033.

Givskov, M., Møller, S., Paulsen, L. K. \& Molin, S. (1994a). Responses to nutrient starvation in Pseudomonas putida K'T2442: analysis of general cross-protection, cell shape, and macromolecular content. J Bacteriol 176, 7-14.

Givskov, M., Eberl, L. \& Molin, S. (1994b). Responses to nutrient starvation in Pseudomonas putida KT2442: two-dimensional electrophoretic analysis of starvation- and stress-induced proteins. J Bacteriol 176, 4816-4824.

Gray, D. I. \& Morris, B. M. (1992). A low cost video analysis system for the $\mathrm{BBC}$ master computer. Binary 4, 58-61.

Hengge-Aronis, R. (1993). Survival of hunget and stress: the role of rpoS in early stationary phase gene regulation in Escherichia coli. Cell 72, 165-168.

Kim, Y., Watrud, L. S. \& Matin, A. (1995). A carbon starvation survival gene of Pseudomonas putida is regulated by $\sigma^{54} . J$ Bacteriol 177, 1850-1859.

Klotz, M. G. \& Anderson, A. J. (1994). The role of catalase isoenzymes in the culturability of the root colonizer Pseudomonas putida after exposure to hydrogen peroxide and antibiotics. Can J Microbiol 40, 382-387.

Mannervik, B. \& Danielson, H. (1988). Glutathione transferase structure and catalytic activity. CRC Crit Rev Biochem 23, 283-337.

Matin, A. (1992). Physiology, molecular biology and applications of the bacterial starvation response. J Appl Bacteriol 73 (Symp Suppl), 495-575.

Meury, J. \& Kepes, A. (1982). Glutathione and the gated potassium channels of Escherichia coli. EMBO J 1, 339-343.

Murata, K., Inoue, Y., Rhee, H. \& Kimura, A. (1989). 2-Oxoaldehyde metabolism in microorganisms. Can J Microbiol 35, 423-431.

Rhee, H., Murata, K. \& Kimura, A. (1987). Metabolism of 2ketoaldehydes in bacteria: oxidative conversion of methylglyoxal to pyruvate by an enzyme from Pseudomonas putida. Agric Biol Chem 51, 1059-1066.

Rowland, G. C., Giffard, P. M. \& Booth, I. R. (1984). Genetic studies of the phs locus of Escherichia coli, a mutation causing pleiotropic lesions in metabolism and $\mathrm{pH}$ homeostasis. FEBS Lett 173, 295-300.

Summer, K. \& Goggelmann, W. (1980). Mutagenicity of 1-fluoro2,4-dinitrobenzene is affected by bacterial glutathione. Mutat Res 70, 173-178.

Zablotowicz, R. M., Hoagland, R. E., Locke, M. A. \& Hickey, W. J. (1995). Glutathione-S-transferase activity and metabolism of glutathione conjugates by rhizosphere bacteria. Appl Environ Microbiol 61, 1054-1060.

Received 27 March 1996; revised 18 June 1996; accepted 27 June 1996. 